\title{
Technology of obtaining a binder for the base of asphalt roads and roofing
}

\author{
Botir Shukrullaev ${ }^{1 *}$, Gulom Bekturdiev ${ }^{1}$, Nurbek Isaev $^{2}$, and Saidbek Omonov ${ }^{3}$ \\ ${ }^{1}$ Institute of General and Inorganic Chemistry of the Academy of Sciences of the Republic of \\ Uzbekistan, Tashkent, Uzbekistan \\ ${ }^{2}$ Tashkent Institute of Irrigation and Agricultural Mechanization Engineers, Tashkent, Uzbekistan \\ ${ }^{3}$ Tashkent State Transport University, Tashkent, Uzbekistan
}

\begin{abstract}
Processing of the local Mubarek oil sludge with subsequent production of a binder for the foundation of highways and roofing. Methods of the utilization of oil sludge were used to obtain a binder. Innovative technology for the production of asphalt pavement by the oxidation method has been developed. Investigations of the chemical composition of the binder for asphalt roads and elemental analysis of dehydration of oil sludge and its homogeneous state are presented.
\end{abstract}

\section{Introduction}

The oil and gas industry takes one of the first places among the leading branches of economic activity in terms of the level of negative impact on the environment. The oil industry is characterized by the formation of a large amount of waste - wastewater and sludge, which are formed in all industrial sectors: during well drilling, development, and operation of oil and gas fields, their field operation, oil and gas transportation, oil treatment and processing, wastewater treatment, as well as when cleaning tanks and other equipment $[1,2,15]$.

Object of study. Industrial sludge from the Mubarek gas production enterprise is a typical waste for energy, transport industrial enterprises, chemical, and metallurgical plants. The processes of forming oily waste in the above industries are mostly similar to those in the oil and gas industry.

To date, the relevance of research is given to the demand for the production of environmentally friendly and sustainable binders for the foundation of roads and roofing from oil sludge. Recycling oil sludge is important to bring it to the required level. They are widely used as binders due to their high viscosity and tackiness. In this regard, it is important to obtain cost-effective binders from local oil sludge and apply them in practice.

There are the following scientific solutions to improve the structure and physicochemical properties of binders for the base of asphalt roads and roofing: selection of local raw materials suitable for the binder, technical and technological re-equipment of enterprises, and reduction of energy consumption; it is necessary to develop technological

\footnotetext{
* Corresponding author: ximtex.botir86@mail.ru
} 
processes for obtaining high-quality binders, to determine the rheological properties of the obtained binders based on colloidal-chemical laws.

In the Republic of Uzbekistan, scientific and practical results have been achieved in developing and applying technology for obtaining binders with improved colloidalchemical properties for asphalt roads and roofing from local oil raw materials and secondary resources.

Literary sources indicate that oil sludge is the largest-tonnage heterophase industrial waste, which predetermines many publications in the field of their study and processing technological processes. But despite this, the volumes of oil sludge placed on the territory of Uzbekistan are not decreasing. According to the latest data, the annual volume of their formation in the Republic of Uzbekistan reaches about 0.5 million tons. In contrast, the volume of use and disposal of this waste is no more than $10 \%$.

Production slimes have a colossal variety of compositions and properties; they are multicomponent systems consisting of water, mechanical impurities (most often, especially for oil production slimes, the components of the geo-environment - silt, clay, sand, etc.), oil (oil products), the ratio of which fluctuates over a very wide range $[2,12,16]$. Using colloidal-chemical approaches to solving issues and using nanotechnology principles, they are working on the development and introduction of binders from oil sludge $[2,13,18]$.

Our research consists of the preparation of a binder from additives and their application in relevant industries.

Basically, sludges are heavy oil residues containing average (by weight) $10-56 \%$ of oil products, $30-85 \%$ of water, and $13-46 \%$ of solid impurities [3].

Oil sludge in pits, in tanks, regardless of the sources of formation, settle over time and are divided into three layers $[4,17]$ :

- the upper layer is low-water-cut oil with a relatively low mass content of mechanical impurities from $0.5 \%$ (for trap oils) to $1.5 \%$ (for storage oils);

- the middle layer is a finely dispersed emulsion of a complex type ("forward" and "reverse") with a mass content of water up to $70-80 \%$ and mechanical impurities of 1.5 $15.0 \%$. The middle layer is usually small in volume. Water and mechanical impurities in it can increase monotonically from top to bottom, can be placed chaotically in volume, and can be distributed almost uniformly;

- the lower, bottom layer - consists of $70 \%$ of the solid phase saturated with oil products (up to $5-10 \%$ ) and water (up to $25 \%$ ); the content of petroleum products is relatively constant, the amount of mechanical impurities increases with depth.

In the oil refining industry, a significant problem is a search for ways of qualified, environmentally balanced, economically viable use of by-products generated in the technological cycles of oil refineries, for some of which options for use in existing products have been proposed $[5,6,19]$. On the other hand, constantly increasing requirements for oil road and construction bitumen determine the need to search for new raw material sources for their production. From this point of view, oil refining by-products are a valuable resource.

The traditional classification of disposal methods $[7,8,20]$ of oil sludge is based on various technologies and represents the following groups:

- thermal - incineration in open pits, furnaces of various types, obtaining bituminous residues, incineration of oil sludge in the form of water emulsions and utilization of released heat and gases, dehydration or drying of oil sludge with the return of oil products to production, and waste water - into the circulating circulation and subsequent burial of solid residues;

- $\quad$ physical - mixing and physical separation of oil sludge;

- chemical - extraction with solvents, curing with additives; 
- physicochemical - the use of specially selected reagents (solvents, demulsifiers, surfactants, etc.) that change the physicochemical properties, followed by processing on special equipment;

- biological - microbiological decomposition in the soil directly at storage sites, biothermal decomposition.

The method of obtaining a binder from oil sludge consists of: - rationing them in terms of moisture and mechanical impurities; - high-speed catalytic oxidation of oil sludge with intense contact with atmospheric oxygen in a mobile unit, rather under mild reaction conditions; - taring after normalization of the properties of the obtained bitumen. According to known methods, petroleum bitumens (asphalt bitumens) are obtained from bituminous oil residue, tar, and heavy oils, by oxidative condensation of their hydrocarbons. This reaction proceeds under rather harsh conditions (with a moderate supply of air heated at 250-3000C and a reaction duration of 3-4 hours) [9, 14].

The aim of the study is a technology for obtaining binders from local oil sludge for the foundation of roads and roofing, taking into account their colloidal-chemical properties and the results of their processing.

According to modern techniques, oil waste and field oil sludge are colloidal systems, the composition of which depends on the degree of dispersion of asphaltenes [10,11].

Towards solving research problems. Studying the classification of methods for the disposal of oil sludge, developing a technology for producing binders for the foundation of asphalt roads and roofing from field oil sludge, determining the chemical and elemental composition of the binder from oil sludge.

Obtaining and using a binder obtained from field oil sludge is one of the urgent tasks for the Republic of Uzbekistan and is included in the category of import-substituting technologies using the best options for compositions of various materials.

\section{Methods}

It is well known that deep processing of various oil sludge is a multi-stage process, requiring complex technological equipment and hard labor, which is included in large-sized devices with fixed energy-intensive structures.

For this reason, an important task is to simplify the process of obtaining binders for the base of asphalt and roofing from liquid oil sludge based on new technology with a light and simple structure and a simple oxidation method at the Institute of General and Inorganic Chemistry of the Academy of Sciences of the Republic of Uzbekistan.

Following the requirements obtained, a mobile experimental device was developed to produce a binder for the foundation of asphalt roads and roofing (Fig. 1). This device is an innovative technology with the following technological parameters:

Below are the operating principles of a test facility for producing a binder for asphalt road base and roofing from liquid oil sludge. Liquid oil sludge settles for 3-4 hours, then, to increase its fluidity by reducing its viscosity, it is heated to about $70-80{ }^{\circ} \mathrm{C}$ poured into container 1 of the device for raw materials, then the gas burner 16 is turned on to increase the temperature in the column, and the metering pipe 15 slowly directs oxidizing air to the bottom of the column. 


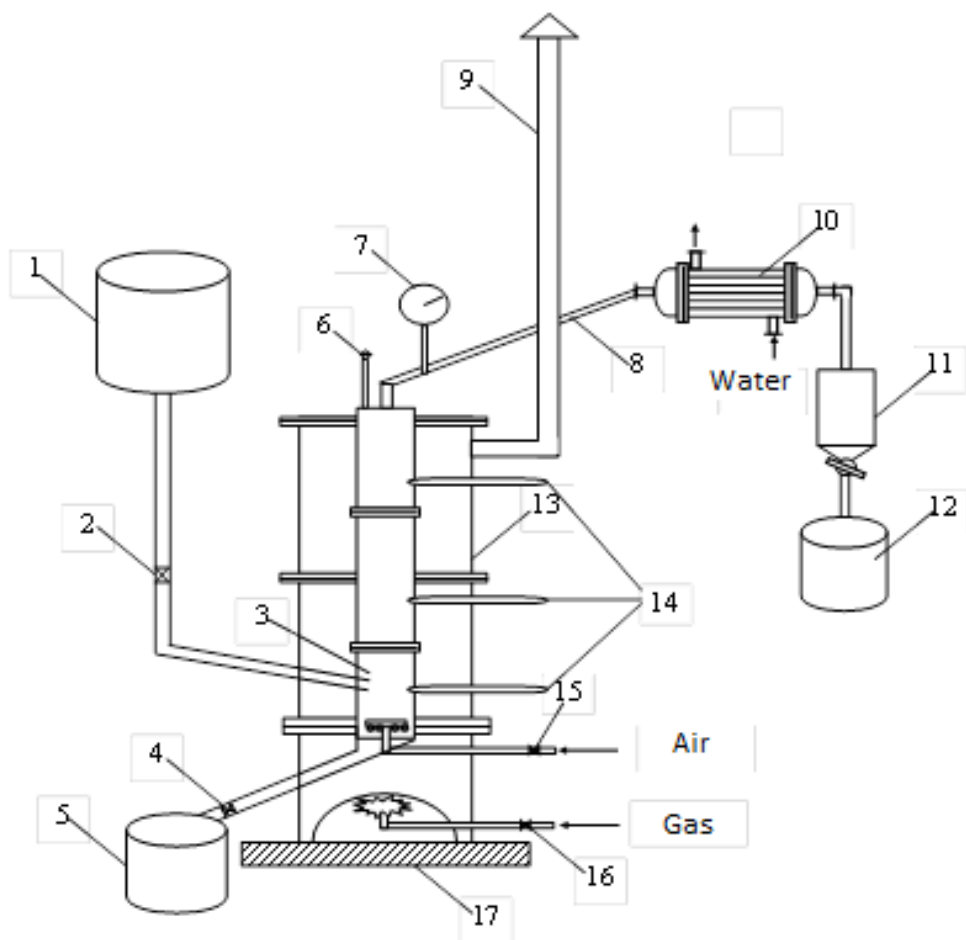

Fig. 1. Technological diagram of a device for obtaining a binder from liquid oil sludge: 1 is container for crude oil; 2 is valve for adjusting the consumption of raw materials; 3 is lane column; 4 is pack for finished products; container for 5 finished products; 6 is pressure relief valve; 7 is manometer for measuring the pressure in the column; 8 is steam outlet pipe; 9 is pipe for exhaust fumes; condenser for cooling the 10 is vapor fraction; 11 is dimensional tube for collecting condensate; 12 is condensate collector; 13 is shell convoy driving; 14 are thermometers for measuring the temperature in the column; 15 is oxidizing air intake pipe; 16 is pipe for fuel gas; 17 is column bottom.

When the temperature in the column rises to $150-160^{\circ} \mathrm{C}$, valve 2 opens and liquid oil sludge is slowly directed downstream to the lower section 3 of the column, and light volatile fractions in the liquid oil sludge evaporate and move upstream from the column and condense through condenser 10 for cooling the vapor fraction through 8 pipes (light fractions in the condenser are cooled with water) and falls into a volumetric flask 11 to collect condensate. Such a volumetric flask serves for the identification and separation of condensed fractions by evaporation temperature. Each fraction is bottled in separate bottles following its fractional composition. Fractions are monitored by 14 thermometers. The column pressure is controlled by 7 pressure gauges. The overpressure is automatically vented to the atmosphere through the outlet valve 6 . As soon as the liquid sludge in the feed tank completely enters the column, valve 2 will close, the temperature in the column will rise to $300^{\circ} \mathrm{C}$, and the air supply will continue. The process ends when the light fractions stop getting into the measuring flask.

At the end of the experiment, the residual fraction is cooled to $50-60^{\circ} \mathrm{C}$ and poured into a separate container. The resulting mass can be used as a binder for the base of asphalt roads and roofing.

The pilot plant assumes that the process is discontinuous and continuous in a continuous fractionation and oxidation reactor. 
The fractions leaving the oil sludge simultaneously leave the top of the column and are also oxidized by injecting atmospheric air into the feed. Oxidation is carried out at $300^{\circ} \mathrm{C}$ for 3-4 hours.

\section{Results and Discussion}

Using the technology of processing various oil sludge, binders for asphalt roads were obtained with subsequent physicochemical parameters. The chemical composition of binders for asphalt roads from oil sludge of these groups is given in Table 1.

Table1. Chemical composition of binders from various oil sludge

\begin{tabular}{|c|c|c|c|c|}
\hline \multirow{2}{*}{$\begin{array}{c}\text { The name of the } \\
\text { group composition of } \\
\text { hydrocarbons }\end{array}$} & $\begin{array}{c}\text { Oil } \\
\text { sludge } \\
\text { mixed } \\
\text { with soil }\end{array}$ & $\begin{array}{c}\text { Natural } \\
\text { oil sludge }\end{array}$ & $\begin{array}{c}\text { Tank oil } \\
\text { sludge }\end{array}$ & $\begin{array}{c}\text { Industrial oil } \\
\text { sludge }\end{array}$ \\
\hline $\begin{array}{c}\text { High molecular } \\
\text { weight paraffinic }\end{array}$ & $42-50$ & $32-35$ & $30-35$ & $25-40$ \\
\hline Aromatic condensed & $8-10$ & $20-25$ & $10-12$ & $20-25$ \\
\hline Aromatic naphthenes & $15-17$ & $20-22$ & $25-35$ & $15-17$ \\
\hline Asphaltene resins & $13-15$ & $10-15$ & $15-20$ & $30-35$ \\
\hline
\end{tabular}

The results obtained in the table show that in the composition of the oil sludge: high molecular weight paraffinic compounds of $25-50 \%$, condensed aromatic compounds of 8$25 \%$, aromatic naphthenes of $15-35 \%$, and asphaltene resins of $13-35 \%$.

The results of elemental analysis of oil sludge dewatering and its homogeneous state are presented in Table 2.

Table 2. Elemental composition of binders from oil sludge

\begin{tabular}{|l|c|c|c|c|c|c|}
\hline \multirow{2}{*}{$\begin{array}{c}\text { Varieties } \\
\text { oil sludge }\end{array}$} & \multicolumn{3}{|c|}{ Elemental composition, \% } & \multirow{2}{*}{\begin{tabular}{c} 
Content of \\
mercaptans, thio \\
\cline { 2 - 5 } compounds, \%
\end{tabular}} & $\begin{array}{c}\text { Mechanical } \\
\text { impurities (complex } \\
\text { metal salts), \% }\end{array}$ \\
\hline Ground & 78.0 & 6.9 & 3.5 & 2.7 & 5.5 & $5.0-8.0$ \\
\hline Bottom & 82.0 & 7.2 & 2.0 & 1.2 & 4.0 & $3.5-4.0$ \\
\hline Reservoir & 85.6 & 8.4 & 1.0 & 0.4 & $0.3-0.5$ & $0.5-0.7$ \\
\hline Field & 88.9 & 8.6 & 0.4 & 0.2 & $0.1-0.2$ & $0.3-0.4$ \\
\hline
\end{tabular}

These tables show that the bonds from different oil sludge differ in their elemental composition. The highest concentration of carbon is found in binders from industrial oil sludge at $88.9 \%$, and the lowest content is found in binders from ground oil sludge at $78 \%$. Binders from industrial oil sludge contain up to $8.6 \%$ hydrogen. As for the oxygen element, the binders from ground oil sludge prevail at $2.7 \%$. The content of mercaptans, thio compounds, and mechanical impurities (complex metal salts) also prevails in these binders, amounting to 5.5 and $5.0-8.0 \%$, respectively. 


\section{Conclusions}

1. It was investigated that the Mubark oil sludge negatively affects the environment. Based on this, the traditional classification of methods for the disposal of oil sludge is considered and has several groups of processing processes.

2. Developed an innovative process of obtaining a binder for the foundation of asphalt roads and roofing from liquid oil sludge by the method of oxidation. Based on the developed technology with a light and not complicated structure at the Institute of General and Inorganic Chemistry of the Academy of Sciences of the Republic of Uzbekistan, a binder was obtained for the foundation of asphalt roads and roofing.

3. The results of the chemical composition of the binder for asphalt roads and roofing from the Mubarek field oil sludge and a variety of oil sludge were obtained elemental analysis of the dehydration of oil sludge and its homogeneous state.

\section{References}

1. Bykov D.E. Development of an integrated multilevel system of research and technologies for processing heterophase industrial waste, Doctor of Technical Sciences dissertation: 03.00.16. - Samara, p 303 (2004).

2. Mazlova E.A., Meshcheryakov S.V. Oil sludge utilization problems and methods of their processing, Publishing house "Noosphere", p 56. (2001).

3. Vaysman Ya. I., Glushankova IS, Rudakova LV, Dyakov MS. Research of physical and chemical properties and thermal destruction of waste from oil refineries, Scientific Research and Innovations, Scientific Journal. 4, (3). p 21-28. (2010)

4. Ermakov V.V, Classification of oil sludge tanks and prediction of the process of biodegradation of waste during their liquidation: Dis. Cand. tech. Sciences: 03.00.16 / GOU VPO "SamSTU". - Samara, p132. (2010).

5. Madumarova Z.R, Study of the influence of the chemical composition of raw materials on the physicochemical properties of oxidized bitumen and the kinetics of the process, author. dis. ... Cand. chem. Sciences: 02.00.13 - Samara,.p 24. (2006).

6. Rozdin I.A. On the classification of industrial waste, Proceedings of MITHT im. Lomonosov,(1). T. IX. p 175.(1979).

7. Zharov O.A, Lavrov V.L, Modern methods of oil sludge processing, Ecology of production. (5) p 43-51.( 2004)

8. Yultimirova, I.A, Problems of oil sludge utilization, Taxes. Investments. Capital, (1). (2004)

9. Shukurullaev B.A., Omonov S.O. Obtaining asphalt bitumen from commercial oil sludge, Coll. Articles V Int. scientific-practical. conf. "Innovative development of science and education" March 23, 2019 - Penza ICNS "Science and Education", 2019, pp.47-49

10. Shukurullaev B.A. Solving the issues of obtaining and using a binder obtained from oil sludge, Universum: technical sciences: electron. scientific. zhurn. 2019. No. 11 (68).

11. Shukurullaev B.A., Khamidov Sh.B. Obtaining an oxidized binder from field oil sludge, Coll. works of the Resp. scientific-practical. conf. "Actual problems of oil and gas purification from impurities by various physical and chemical methods", April 27, pp. 121-123.(2019).

12. Fuchs G.I. Viscosity and plasticity of petroleum products. - M. - Izhevsk: Institute of Computer Research, p 328. (2003). 
13. Pozdnyshev G.N, Modern achievements in the field of oil treatment, G.N. Pozdnyshev, A.A. Emkov, ser. Oilfield business: - Overview information. p 50. (1979)

14. Pokonova Yu. Oil and oil products. Directory. - M .: Chemistry, p 515 (2005).

15. Pimenov A.A. Waste and Residue Management of Chemical and Petrochemical Enterprises Using Their Resource Potential, Dis. Cand. tech. Sciences: 03.02.08 / GBOU VO "SamSTU". - Samara, p 254. (2017).

16. Shornikova, E.A, Some possible ways of utilization of drilling and oil production waste , Biological resources and environmental management. - Surgut. - 2002. (5). p 99-109. (2002).

17. Shperber E.R., Bokovikova T.N., Shperber D.R. Sources of oil sludge formation and methods of their utilization, Chemistry and technology of fuels and oils. 2011. (2). - p. 53-56. (2011).

18. Eyvazova A. G., Nesmeyanova R. M, Oil sludge and possible areas of its use, Modern techniques and technologies: collection of works of the XVIII international scientificpractical conference of students, graduate students and young scientists. - Tomsk, 2012, T. (3). p. 147-148. (2012).

19. Jing Golin, Luan Mingming, Chen Tingting, Prospects for the development of oil sludge processing processes, Chemistry and technology of fuels and oils (4). p. 44-54. (2011).

20. Yagafarova G.G., Barakhnina V.B. Utilization of environmentally hazardous drilling waste, Oil and Gas Business. (2006) 